ANUVA Volume 2 (2): 117-125, 2018

Copyright (C2018, ISSN: 2598-3040 online

Available Online at: http://ejournal.undip.ac.id/index.php/anuva

\title{
Community of Practice Sebagai Wadah Berbagi Pengetahuan Berdimensi Teknis dan Kognitif
}

\author{
Yanuar Yoga Prasetyawan ${ }^{*}$ \\ ${ }^{1}$ Program Studi Ilmu Perpustakaan, Fakultas Ilmu Budaya, Universitas Diponegoro, \\ Jl. Prof. Soedarto, SH, Kampus Undip Tembalang, Semarang, Indonesia 50275
}

*Korespondensi: yanuaryoga@ live.undip.ac.id

\begin{abstract}
Knowledge is an intangible asset for the information society. Through knowledge as a capital, it able to produce work and innovation. To increase the potential for innovation, it is necessary to conduct knowledge merging activities through knowledge sharing activities. Knowledge-sharing activities are vulnerable to constraints, especially for knowledge that has both cognitive and technical dimensions. Because the most effective way to share knowledge that has two dimensions is through practice. Knowledge sharing activities are popular with the term Community of Practice.
\end{abstract}

Keyword: knowledge; knowledge sharing; community of practice

\begin{abstract}
Abstrak
Pengetahuan merupakan aset tak berbentuk (intangible) bagi masyarakat informasi. Melalui pengetahun sebagai modal, mampu menghasilkan karya dan inovasi. Untuk meningkatkan potensi terciptanya inovasi perlu dilakukan kegiatan penggabungan pengetahuan melalui aktifitas berbagi pengetahuan. Aktifitas berbagi pengetahuan rentan mengalami kendala terutama bagi pengetahuan yang memiliki dua dimensi baik kognitif maupun teknis. Karena cara yang paling efektif untuk membagi pengetahuan yang memiliki dua dimensi tersebut adalah melalui praktik. Aktifitas berbagi pengetahuan tersebut populer dengan istilah Community of Practice.
\end{abstract}

Kata kunci: pengetahuan; berbagi pengetahuan; komunitas praktik

\section{Pendahuluan}

Marak dan menjamurnya komunitas hobi atau profesi tertentu di kalangan masyarakat Indonesia dewasa ini menjadi sinyal positif bagi pengembangan kualitas hidup masyarakat Indonesia. Perihal tersebut nampak pada kegiatan yang diselenggarakan oleh komunitas tersebut. Kegiatan yang mereka lakukan diantaranya adalah berkumpul dan saling berbagi pengalaman terhadap hobi atau pekerjaan yang mereka lakukan. Sebagai contoh misalnya, di dunia kepustakawanan Indonesia kini menjamur komunitas pengguna sistem informasi perpustakaaan SLiMS (Senayan Library Management System). Mereka menamai komunitasnya dengan nama komunitas dan kota domisili tempat komunitas tersebut berasal misalnya, 
Komunitas SLiMS Jogja, Komunitas SLiMS Kudus, dan lain sebagainya. Profesi yang bergabung dalam komunitas tersebut tidak hanya pustakawan saja, melainkan juga para professional teknologi informasi. Para professional tersebut bergabung karena SLiMS juga merupakan sitem informasi yang juga merupakan ranah kajian keilmuan teknologi informasi

Kegiatan yang dilakukan oleh komunitas SliMS tersebut adalah saling berbagi pengetahuan dan pengalaman mereka dalam menggunakan dan mengaplikasikan SLiMS. Kegitan tersebut memberikan keuntungan bagi banyak pihak. Keuntungannnya misalnya, bagi pengguna SLiMS yang masih awam dapat belajar langsung dengan anggota yang lebih ahli dalam mengoperasikan SLiMS. Keuntungan yang lain juga dapat diterima oleh para pengembang SLiMS, mereka mendapatkan saran ataupun keluhan dari komunitas penggunanya untuk pengembangan SLiMS agar menjadi sistem informasi perpustakaan yang terus menerus disempurnakan.

Dari fenomena tersebut menunjukan bahwa pengetahuan merupakan aset yang sangat berharga dan penting untuk dapat dikelola dengan baik, sehingga mampu memberikan nilai lebih bagi yang memanfaatkannya. Dalam tulisan ini akan dibahas pendekatan secara teoritis mengenai hubungan antara mengelola pengetahuan, berbagi pengetahuan, dan cara atau metode berbagi pengetahuan khusus melalui wadah Community of Practice.

\section{Mengelola Pengetahuan melalui Berbagi Pengetahuan (Knowledge Sharing)}

Bagi masyarakat abad 21 saat ini aset utama mereka tidak hanya terbatas pada barang berharga seperti rumah, emas, mobil, dan sebaginya, namun juga informasi dan pengetahuan. Pengertian mengenai pengetahuan amat luas, kontekstual, bahkan sangat personal, ada yang mengartikan pengetahuan adalah informasi yang ada di dalam pikiran. Dalam konteks tulisan penelitian ini penulis mengartikan pengetahuan merupakan kebiasaan, kehlian atau kepakaran, ketrampilan, pemahaman yang diperoleh melalui proses belajar seseorang (Yusup: 2012). Menurut sifatnya, terdapat dua jenis pengetahuan yaitu: pengetahuan tacit merupakan pengetahuan yang masih tersimpan pada diri seseorang dan belum dikodifikasi atau disimpan dalam sebuah media dokumentasi, dan pengetahuan explicit yaitu pengetahuan yang sudah dikodifikasi dan disimpan dalam sebuah media dokumentasi (Nonaka dan Takeuchi: 1995).

Pengetahuan yang bermanfaat dan bernilai perlu diciptakan, diorganisasi, dibagikan, dan disalurkan, oleh karena itu diperlukan usaha untuk memastikan pengetahuan agar diciptakan, ditangkap, diorganisasi,serta dapat diakses dan digunakan sebagai asset yang berharga untuk keparluan pengembangan diri, istilah tersebut lebih populer dengan sebutan knowledge management. Dalam konteks tulisan pada penelitian ini knowledge management dirtikan sebagai sebuah usaha terciptanya atmosfer atau suasana saling berbagi pengetahuan dan mengembangkan pengetahuan antar individu karena pengetahuan telah dianggap sebagai komoditas utama (Clair dan Stanley: 2010).

Definisi knowledge management tersebut di atas menyebutkan kalimat berbagi pengetahuan (knowledge sharing) yang merupakan tujuan utama dilakukannya kegiatan knowledge management. David Gurteen menjelaskan istilah knowledge sharing merupakan suatu konsep yang menggambarkan interaksi 
antar orang, dua orang atau lebih, dalam bentuk proses komunikasi yang bertujuan peningkatan dan pengembangan diri tiap anggotanya (Yusup: 2010). Melalui kegiatan berbagi pengetahuan (knowledge sharing) tidak menutup kemungkinan untuk terciptanya pengetahuan baru sehingga menghasilkan sebuah inovasi baru, kegiatan tersebut dapat diilustrasikan pada gambar 2.1 (siklus knowledge sharing) berikut ini:

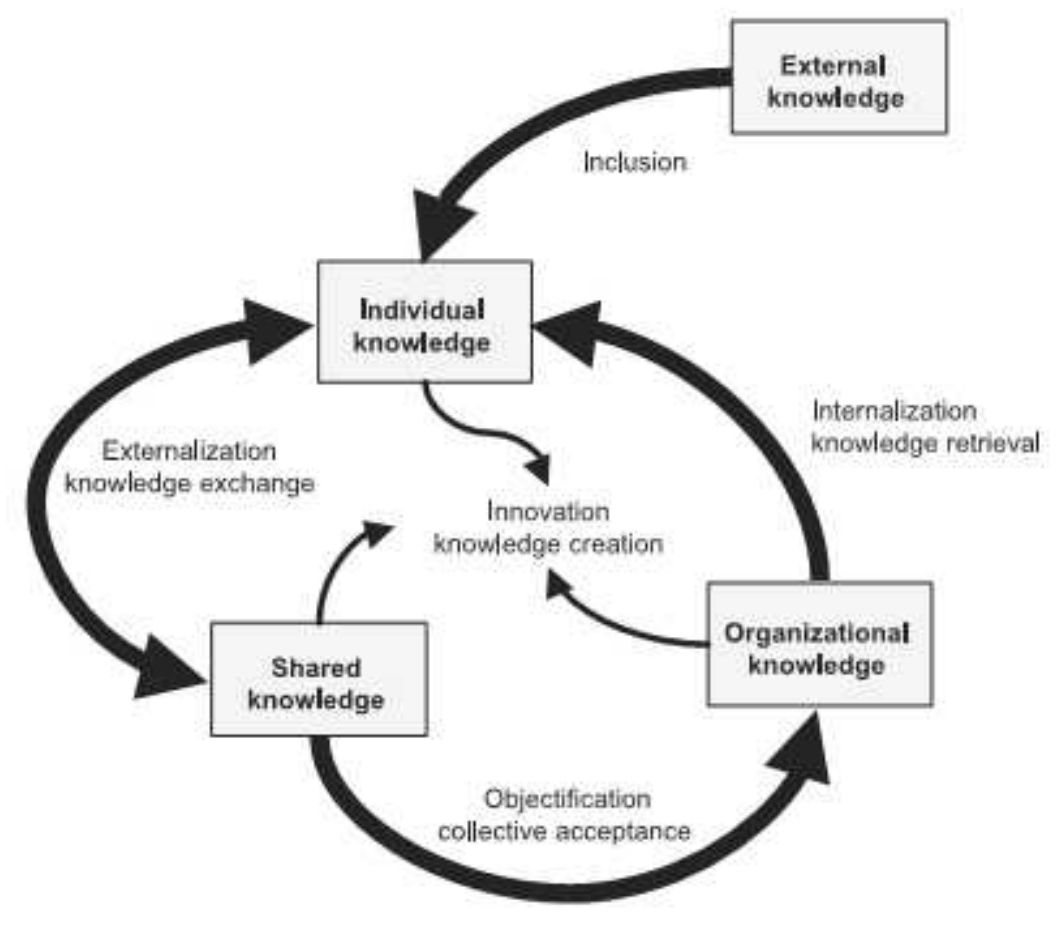

Gambar 1

Sikuls Knowlede Sharing

Sumber: Ackerman (2003)

Gambar diatas menunjukan tiga tipe mendasar dalam knowledge sharing, antara lain:

1. Knowledge retrieval. Berbagi pengetahuan dari organisasi ke individu memiliki tujuan mengambil pengetahuan yang ada pada organisasi, selama pengambilan pengetahuan individu belajar dari organisasi. Tipe knowledge sharing ini digambarkan pada gambar 2.1 dengan panah yang menunjuk dari pengetahuan organisasi (organizational knowledge) ke pengetahuan individu (individual knowledge).

2. Knowledge exchange. Berbagi pengetahuan dari individu ke individu yang lain memiliki tujuan pertukaran pengetahuan antara individu yang ada. Pertukaran pengetahuan diilustrasikan dengan panah yang menunjuk dari pengetahuan individu ke shared knowledge (pengetahuan yang dibagikan)

3. Knowledge Creation. Berbagi pengetahuan antar individu memiliki tujuan untuk menciptakan pengetahuan baru. Kombinasi antara Individual Knowledge, Shared Knowledge, dan Organizational Knowledge menciptakan pengetahuan baru. Perihal ini digambarkan dengan 
panah dari masing-masing ketiga jenis pengetahuan tersebut menuju satu titik "innovation knowledge creation".

Siklus knowledge sharing di atas menunjukan adanya transfer pengetahuan dari individu yang satu ke individu lainnya, baik pengetahuan yang bersifat tacit maupun pengetahuan yang bersifat explicit, namun pengetahuan yang bersifat tacit relatif lebih sulit untuk diverbalisasikan atau diungkapkan dengan kata-kata dan ditransfer dari pada pengetahuan yang bersifat explicit. Pengetahuan yang bersifat tacit lebih mudah ditransfer dengan cara menunjukan seseorang untuk melakukan sesuatu dari pada mencoba untuk menjelaskan dengan kata-kata, terlebih lagi jika pengetahuan tacit tersebut merupakan pengetahuan yang berkaitan dengan ketrampilan atau keahlian seseorang dalam melakukan suatu kegiatan. Hal tersebut terjadi dikarenakan pengetahuan tacit memiliki dua karakteristik dimensi berikut ini (Nonaka dan Takeuchi: 1995):

1. Dimensi teknis. Dimensi ini bersifat informal dan mengetahui bagaimana cara (know how) dalam melakukan sesuatu. Dimensi teknis mengandung prinsip dan teknis pengetahuan yang diperoleh karena pengalaman oleh karena itu sulit untuk didefinisikan atau diverbalisasikan.

2. Dimensi kognitif. Dimensi ini terdiri dari kepercayaan, persepsi, idealism, nilai-nilai, emosi dan mental yang juga sulit untuk di jelaskan. Dimensi ini akan membentuk cara seseorang menerima segala sesuatu yang ada di sekelilingnya.

\section{Berbagi Pengetahuan Melalui Wadah Communities of Practice}

Karena sifat pengetahuan tacit yang sulit untuk diverbalisasikan sehingga lebih mudah dengan cara menunjukan seseorang untuk melakukan sesuatu, maka konsep Communities of Practice menawarkan solusi yang sesuai dengan kondisi tersebut. Konsep Communities of Practice pertama kali diperkenalkan oleh Etienne Wenger, menurut dia definisi Communities of Practice adalah sekelompok orang yang saling berinteraksi dalam berbagi minat dan hobinya, kemudian mereka saling belajar satu sama lain untuk menjadi lebih baik dalam minat dan hobinya tersebut (Wenger, McDemort, dan Snyder: 2002).

Communities of Practice sebenarnya bukanlah sebuah konsep yang baru, konsep ini merupakan adaptasi dari konsep awal mula sebuah struktur sosial yang berbasis pengetahuan (first knowledge-based social structures), kegiatan ini sudah berlangsung sejak jaman dahulu kala ketika manusia masih tinggal di dalam gua, berkumpul mengelilingi api unggun kemudian mendiskusikan strategi untuk menangkap hewan buruan atau mendiskusikan jenis tumbuhan yang dapat dapat dimanfaatkan atau berbahaya bagi manusia. Communities of Practice ada di mana-mana, kita semua menjadi bagian darinya, di tempat kerja, di rumah, di sekolah, di dalam hobi kita, beberapa Communities of Practice mempunyai nama, beberapa tidak, beberapa dapat dikenali, beberapa tersembunyi. Apapun bentuk komunitas yang kita ikuti, baik itu komunitas formal maupun informal atau apapun bentuknya, kebanyakan dari kita sangat akrab dan memiliki pengalaman menjadi anggota dari sebuah Communities of Practice.

Bentuk dari Communities of Practice sangatlah beragam tergantung pada tujuan dan kebutuhan kelompok pembentuk komunitas tersebut, namun struktur mendasarnya adalah kegiatan saling berbagi 
pengetahuan. Communities of Practice merupakan kombinasi unik yang terdiri dari tiga elemen fundamental yaitu domain atau bidang pengetahuan, community atau sekumpulan orang pemerhati bidang pengetahuan tersebut, dan shared practice yaitu kegiatan berbagi pengetahuan melalui praktik untuk meningkatkan kemampuan pada domain tersebut (Wenger, McDemort, dan Snyder: 2002). Berikut ini akan dijelaskan lebih lanjut mengenai ketiga elemen fundamental dalam Communities of Practice:

1. Domain menciptakan ground (dasar) yang sama serta perasaan kesamaan identitas. Untuk dapat mendefinisikan domain yang baik, komunitas harus mampu mengukuhkan tujuan dan nilai atau manfaatnya bagi anggota. Domain memberikan dorongan bagi anggotanya untuk berkontribusi dan berpartisipasi. Cakupan domain yang jelas membantu para anggota untuk mampu menentukan dengan tepat mengenai pengetahuan yang akan mereka bagi.

2. Community menciptakan jaringan sosial kegiatan pembelajaran. Komunitas yang kuat akan mendorong interaksi dan hubungan yang saling percaya dan menghormati, hal ini akan mendorong keinginan untuk berbagi ide, mengungkap masalah, bertanya dan mendengarkan dengan seksama antar individu.

3. Practice merupakan seperangkat kerangka pemikiran, ide, alat informasi, gaya bahasa, cerita, serta dokumen mengenai kegiatan saling berbagi pengetahuan antara anggota komunitas.

Memperhatikan sifat dari Community of Practice tersebut serta melihat kegiatan dan aktifitas yang dilakukan oleh Komunitas SLiMS di Indonesia, apa yang dilakukan oleh komunitas SLiMS merupakan kegiatan berbagi pengetahuan melalui wadah Community of Practice. Karena sifat pengetahuan tacit yang dibagikan mengandung dimensi teknis yaitu mengenai pengetahuan dan pengaalaman dalam mengoperasikan sitem informasi perpustakaan SLiMS maka kegiatan berbagi pengetahuan lebih efektif dengan cara sharing by doing. Komunitas SLiMS juga memenuhi tiga elemen fundamental pembentuk Community of Practice, yaitu: Domain mereka adalah sitem informasi perpustakaan SLiMS, Community mereka adalah para pengguna SLiMS, Practice mereka adalah kegiatan saling berbagi pengetahuan dan pengelaman dalam menggunakan SLiMS.

Berfungsi sebagai elemen utama dan fundamental, Wenger, McDemort, dan Snyder (2002) menyatakan bahwa ketiga elemen dari Communities of Practice tersebut dapat pula menjadi panduan praktis untuk mengembangkan komunitas.

1. Domain. Merundingkan fokus bidang pengetahuan bersama sangatlah penting bagi perkembangan anggota, komunitas melakukan evaluasi dan mengintrospeksi diri menggunakan beberapa pertanyaan berikut: bidang pengetahuan apakah yang benar-benar akan kita perhatikan?, bagaimana bidang pengetahuan ini dapat terhubung dengan organisasi kita?, apa manfaat domain ini bagi kita?, dampak yang bagaimanakah yang hendak kita capai dengan domain ini? Apakah kita siap untuk memimpin mempromosikan dan mengemangkan domain kita?. Dengan memetakan pertanyaan tersebut maka komunitas akan terbantu untuk mengembangkan pemahaman bersama tentang domainnya sehingga menumbuhkan gairah berkomunitas bagi anggotanya. 
2. Community. Unsur masyarakat perlu mendapatkan perhatian, diorganisasi, dan dipelihara. Aturan apa yang akan dijalankan?, seberapa sering anggota saling bertemu, dan bagaimana caranya tiap anggota akan tetap terhubung?, jenis kegiatan yang bagaimana yang akan mengeratkan hubungan para anggota?, bagai mana cara komunitas memenuhi segmentasi kebutuhan anggotanya?, bagai mana cara menangani konflik yang terjadi?, bagaimana cara menyambut anggota baru? Dengan menyikapi pertanyaan tersebut maka komunitas akan mampu untuk membangun hubungan sehingga dapat tumbuh berkembang.

3. Practice. Masyarakat komunitas yang beriteraksi secara terus menerus mengenai sebuah bidang pengetahuan akan mengembangkan beberapa jenis latihan atau praktek. Pengetahuan apa yang akan dibagi, dikembangkan, dan didokumentasikan?, gaya belajar yang bagaimana yang akan diterapkan?, bagai mana seharusnya repository pengetahuan diorganisasi untuk mencerminkan kegiatan praktik serta mudah untuk diakses oleh para anggota?, proyek pembangunan apakah yang seharusnya dikerjakan oleh komunitas?, bagaimana mengakses sumber pengetahuan yang berada diluar komunitas?. Jenis pertanyaan ini akan menjadikan komunitas sebagai sumber pengetahuan yang efektif bagi anggotanya.

Communities of Practice membutuhkan interaksi antar para anggotanya agar dapat terus bertahan dan menjadi komunitas yang hidup, untuk dapat terus bertahan, berdasarkan pengalaman Wenger, McDemort, dan Snyder (2002) mereka merumuskan tujuh prinsip untuk membudidayakan Communities of Practice, antara lain:

\section{Design for Evolution}

Sifat komunitas yang dinamis dan berkeinginan untuk terus berkembang searah dengan perkembangan jaman dan kebutuhan anggotanya adalah kunci keberhasilan prinsip ini. Struktur social dan organisasi seperti kordinator komunitas atau pertemuan rutin komunitas akan mengendapkan sebuah evolusi komunitas.

2. Open dialogue between inside and outside perspectives

Komunitas yang baik selalu memperhatikan perspektif insider (anggota intern komunitas), karena merekalah yang dapat merumuskan masalah utama apakah yang harusnya menjadi fokus domain mereka, pengetahuan jenis apa yang perlu untuk dibagikan, apa sajakah tantangan yang dihadapi di lapangan, serta jenis potensi apakah yang perlu dimunculkan untuk menghasilkan ide dan teknik baru. Jadi bukan hanya sekedar memperhatikan input yang telah diberikan, namun juga output yang diinginkan untuk dapat menjadi lebih baik dalam domain yang menjadi fokus komunitas. Namun, jika ternyata sumber pengetahuan yang berkompetensi tidak terdapat di dalam komunitas tapi di luar komunitas, maka dibutuhkan peran pimpinan komunitas untuk dapat mengundang outsider atau sumber pengetahuan luar komunitas untuk berbagi pengetahuannya di dalam komunitas.

3. Invite different levels of participation 
Setiap orang atau anggota dalam komunitas memiliki alasan dan motivasi yang berbeda untuk bergabung dan berpartisipasi dalam komunitas, ada yang bergabung karena komunitas tersebut mempunyai manfaat dan nilai bagi mereka, ada yang bergabung hanya untuk menjalin koneksi personal, ada juga yang bergabung karena termotivasi untuk meningkatkan kemampuannya dalam suatu bidang, hal tersebut mutlak ada dalam setiap jenis komunitas. Terdapat tiga tingkatan atau level partisipasi dalam berkomunitas yang diilustrasikan pada gambar 2.2 berikut ini:

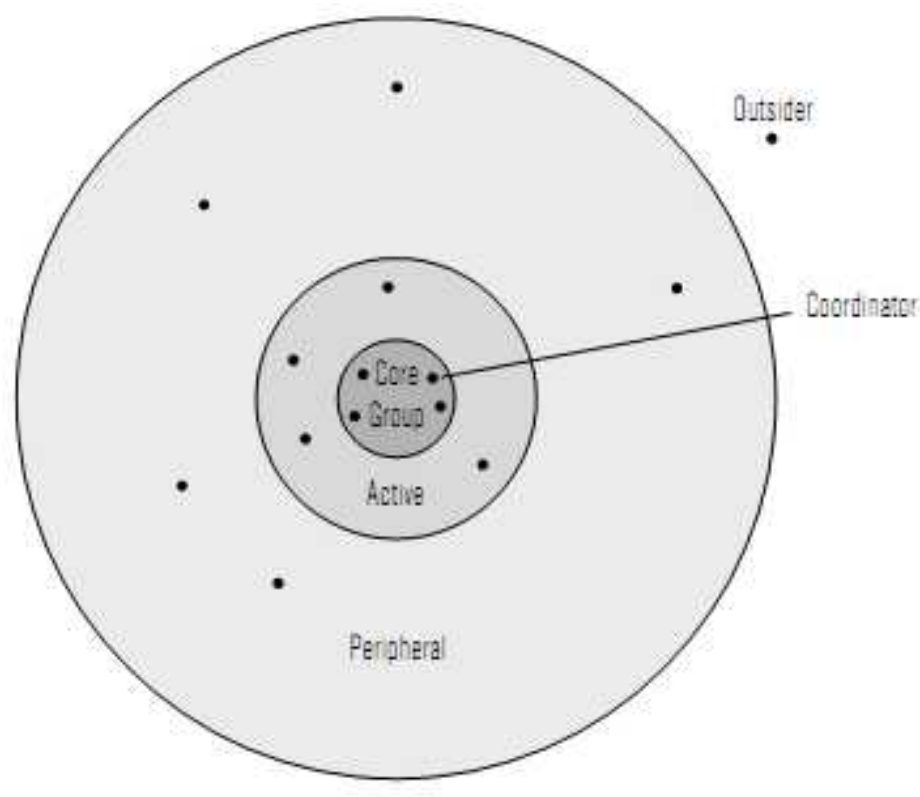

Gambar 2

Tingkatan atau level partisipasi anggota komunitas

Sumber: Wenger, McDemort, dan Snyder: 2002

Tingkat pertama adalah core group (cenderung berjumlah sedikit berkisar antara 10\% - 15\%) mereka adalah orang yang paling aktif berpartisipasi berdiskusi dan berdebat di dalam forum komunitas. Mereka merupakan jantungnya komunitas, hidup matinya komunitas bergantung pada mereka, mereka yang paling berpengaruh dan berperan dalam menentukan kegiatan dan menetukan topik atau bahasan utama komunitas mereka. Tingkatan ke dua adalah active group, mereka merupakan anggota yang menghadiri pertemuan secara teratur dan berpartisipasi dalam kegiatan komunitas, jumlah mereka juga relative masih sedikit yaitu berkisar anatara $15 \%$ $20 \%$ dari jumlah keseluruhan anggota. Jumlah terbesar dari anggota komunitas adalah peripheral and rarely group, mereka adalah anggota yang jarang aktif untuk berpartisipasi dalam komunitas, namun mereka tetap memperhatikan interaksi dan kegiatan yang dilakukan oleh core dan active members, kare sesungguhnya mereka tidak sepasif apa yang terlihat, mereka juga memiliki potensi untuk berpengaruh dalam lingkungan sekitar, inilah kekuatan 
potensial dari komunitas untuk dapat menarik outsider mau masuk bergabung dan aktif dalam komunitas.

\section{Develop both public and prival community spaces}

Komunitas yang dinamis adalah komunitas yang memiliki koneksi yang kaya baik mengenai ruang publik komunitas yaitu kegiatan pertemuan, website yang berisi berita kegiatan komunitas, dan ruang privat yaitu hubungan orang per orang antar anggota komunitas. Melalui kegiatan yang bersifat terbuka untuk public (public space) komunitas mampu menarik perhatian outsider dan potential member. Dengan meningkatkan kegiatan baik yang bersifat publik atau privat akan menguatkan hubungan antar individu para anggotanya.

5. Focus on value

Komunitas akan semakin kuat dan kokoh jika mereka tetap berfokus pada manfaat bersama berdasarkan kebutuhan anggota komunitas

6. Combine familitary and excitement

Komunitas yang baik dan sukses selalu memberikan kenyamanan, kegembiraan, suasana akrab, dan kekeluargaan, melalui suasana tersebut maka para anggota akan dapat dengan bebas, nyaman, dan jujur mengungkapkan pendapatnya, berbagi ide, bercerita keluh kesahnya, tanpa adanya tekanan

7. Create a rhythm for the community

Communities of Practice arus memiliki ritme dalam perjalanannya berkomunitas, mengatur tempo pertemuan rutin mingguan atau bulanan, melakukan pertemuan informal seperti makan bersama, membangun website komunitas, melakukan telekonferensi, semua kegiatan tersebut akan lebih memacu detak jantung komunitas untuk menjadi komunitas yang hidup dan berkembang. Jika detak jantungnya terlalu cepat komunitas harus responsive dan memperlambat laju kegiatan komunitas, namn jika terlalu lambat komunitas harus segera memacu kembali detak jantungnya dengan kembali mengadakan aktifitas atau kegiatan komunitas.

\section{Simpulan}

Tidak semua jenis pengetahuan tacit dapat secara efektif dibagikan hanya dengan berdiskusi atau ceramah. Karena sifat dari pengetahuan tacit memiliki 2 dimensi yaitu dimensi kognitif dan dimensi teknis. Dimensi teknis tersebut memaksa setiap individu yang ingin membagikan pengetahuannya harus disertai dengan kegiatan praktik. Oleh karena itu konsep Community of Practice hadir sebagai jawaban atas permasalahan tersebut. Melalui kegiatan berbagi pengetahuan dengan metode yang tepat, maka pengetahuan yang merupakan aset intangible (tak berbentuk) dan memiliki nilai lebih tersebut dapat dimanfaatkan dan dikelola agar dapat menumbuhkan dan menciptakan inovasi baru. 


\section{Daftar Pustaka}

Ackerman, Mark S., Pipek, Volkmar, dan Wulf, Volker. (2003). Sharing Expertise : Beyond Knowledge Management. London: The MIT Press

Nonaka, Ikujiro dan Takeuchi, Hirotaka. (1995). The Knowledge-Creating Company: How Japanese Companies Create the Dynamics of Innovation. New York: Oxford University Press

Wenger, Eitenne, McDemort, Richard, dan Snyder, William. (2002). Cultivating Communities Of Practice : A Guide To Managing Knowledge. Massachusetts: Harvard Business School Press

Yusup, Pawit M. (2012). Perspektif Manajemen Pengetahuan Informasi, Komunikasi, Pendidikan, dan Perpustakaan. Jakarta: PT Raja Grafindo Persada 